\title{
A FRAMEWORK FOR CRANE SELECTION IN LARGE-SCALE INDUSTRIAL CONSTRUCTION PROJECTS
}

\author{
* SangHyeok Han ${ }^{1}$, Shafiul Hasan ${ }^{1}$, Zhen Lei ${ }^{1}$, Mohammed Sadiq Altaf ${ }^{1}$, Mohamed Al-Hussein ${ }^{1}$ \\ ${ }^{I}$ Department of Civil and Environmental Engineering, \\ University of Alberta \\ Edmonton, AB, Canada T6G $2 G 7$ \\ (*Corresponding author: sanghyeo@ualberta.ca)
}

\begin{abstract}
Selecting the best possible cranes and identifying spatial conflict-free locations on sites can result in productivity and safety improvements for large-scale industrial construction projects. In the current practice, experienced lift engineers select cranes based on the heaviest lift and/or the largest lifting radius of the identified crane. This practice is relatively time-consuming, and optimization of the crane's use and location is also difficult. There are many factors which need to be considered during the crane selection process, a reality which further complicates the process. This paper presents a framework which aims at developing a decision support system to enhance the crane selection process and collision-free path planning for large-scale construction projects. This paper utilizes an innovative crane selection matrix in order to establish a process for optimized crane selection for construction projects. The study considers more than 40 different factors in order to reduce time and improve safety for crane operations. Following finalization of crane type (mobile crane versus tower crane), a visualization model to simulate crane operation and identify collision-free crane operation paths is proposed. This process can assist project managers to plan the lifting process more effectively and efficiently. A case study-based approach was utilized to demonstrate the proposed methodology. The methodology was tested in the planning and construction process for boiler house structures in Mannheim, Germany. The project entailed numerous challenges: one of the major tasks was to lift a 102-ton load on the top of the boiler structure through crane collaboration; space limitations on site also presented several challenges related to crane selection, location, and operation processes. Based on the project constraints, the proposed crane selection framework, and the visualization models, two tower cranes were selected and successfully implemented in the case study.
\end{abstract}

\section{KEYWORDS}

Optimum crane selection, Crane selection matrix, Visualization, Heavy structure

\section{INTRODUCTION}

In industrial construction projects, the utilization of cranes often relates to the project budget and scheduling control. Inappropriate planning of crane operations can lead to cost overruns and schedule delays. In particular, the selection of crane types and locations plays a crucial role in the entire crane lift planning. To this end, analysis results are usually generated at the beginning stage of the project which will consequently have an impact on the entire construction process. In order to determine the suitable crane type and reasonable positions, many factors are taken into consideration, such that the analysis is conducted considering the heaviest lift or the largest lifting radius as the priority in the analysis. A fuzzy logic approach has been proposed by Hanna and Lotfallah (1999) to select the best crane type. Two types of factors, dynamic and static, are considered in order to select the crane type among mobile, tower, and derrick cranes. An algorithm has been proposed by Al-Hussein, Alkass, and Moselhi (2001) for selecting and locating mobile cranes on construction sites with the most suitable crane configurations and corresponding lift settings. Sawhney and Mund (2002) presented the features of a prototype crane selection tool, so-called IntelliCranes. The presented system considered three types of crane types and several craneselecting parameters (such as type of crane use, duration, construction height, etc.). However, it did not check for potential collisions of the selected crane with its surrounding environment, which implies that the selected crane may not have feasible lifting paths in practice. Wu, Lin, Wang, Wang, and Gao (2011) proposed an algorithm for selecting mobile cranes, considering the lifting capacity and the geometry of the 
crane, among other factors. Although incorporated with the 3D visualization model, the proposed system is limited to the selection of mobile crane types, and cannot be applied more generally for other types of cranes. An optimization model has been proposed for selecting the tower crane and material supply locations for high-rise building sites using mixed-integer linear programming (Huang, Wong, \& Tam, 2011). Other crane and location selection-related works include Kang and Miranda (2006); Safouhi, Mouattamid, Hermann, and Hendi (2011); and Olearczyk, Al-Hussein, Bouferguène, and Telyas (2012). Meanwhile, apart from the crane type and location selections, practitioners have been developing useful tools or algorithms to assist with crane lift planning from other perspectives: crane path planning (Sivakumar, Varghese, \& Babu, 2003; Chang, Hung, \& Kang, 2012; Lei, Taghaddos, Hermann, \& AlHussein, 2013); crane lift sequencing (Hermann, Hendi, Olearczyk, \& Al-Hussein, 2010; Taghaddos, AbouRizk, Mohamed, \& Hermann, 2012); and the environmental impact of on-site crane operations (Hasan, Bouferguène, Al-Hussein, Gillis, \& Telyas, 2013). In this paper, a newly developed decision support system is proposed for crane selection and collision-free path planning for industrial construction projects. The crane selection is based on an innovative crane selection matrix that accounts for more than 40 factors concerning construction efficiency and safety. Both mobile cranes and tower cranes are taken into account in analyzing the best crane selection option, based upon which a visualization model is utilized to simulate crane operations and plan feasible lift paths. The proposed methodology has been tested and validated through implementation in a boiler house structure located in Mannheim, Germany, which features congested operational space and massive loads. Figure 1 presents the proposed methodology, which consists of two main components: (1) crane selection; and (2) collision-free path planning. The inputs include: (1) crane selection categories, factors, and sub-factors; (2) questionnaire feedback to determine the weighting of the categories and factors; (3) crane information, such as crane type and capacity; and (4) site obstructions which are used to develop the 3D visualization. The methodology is also subject to the following criteria: (1) available crane type; (2) site information such as space limited, location and accessibility; (3) weather conditions; and (4) the neighbourhood surrounding the construction site.

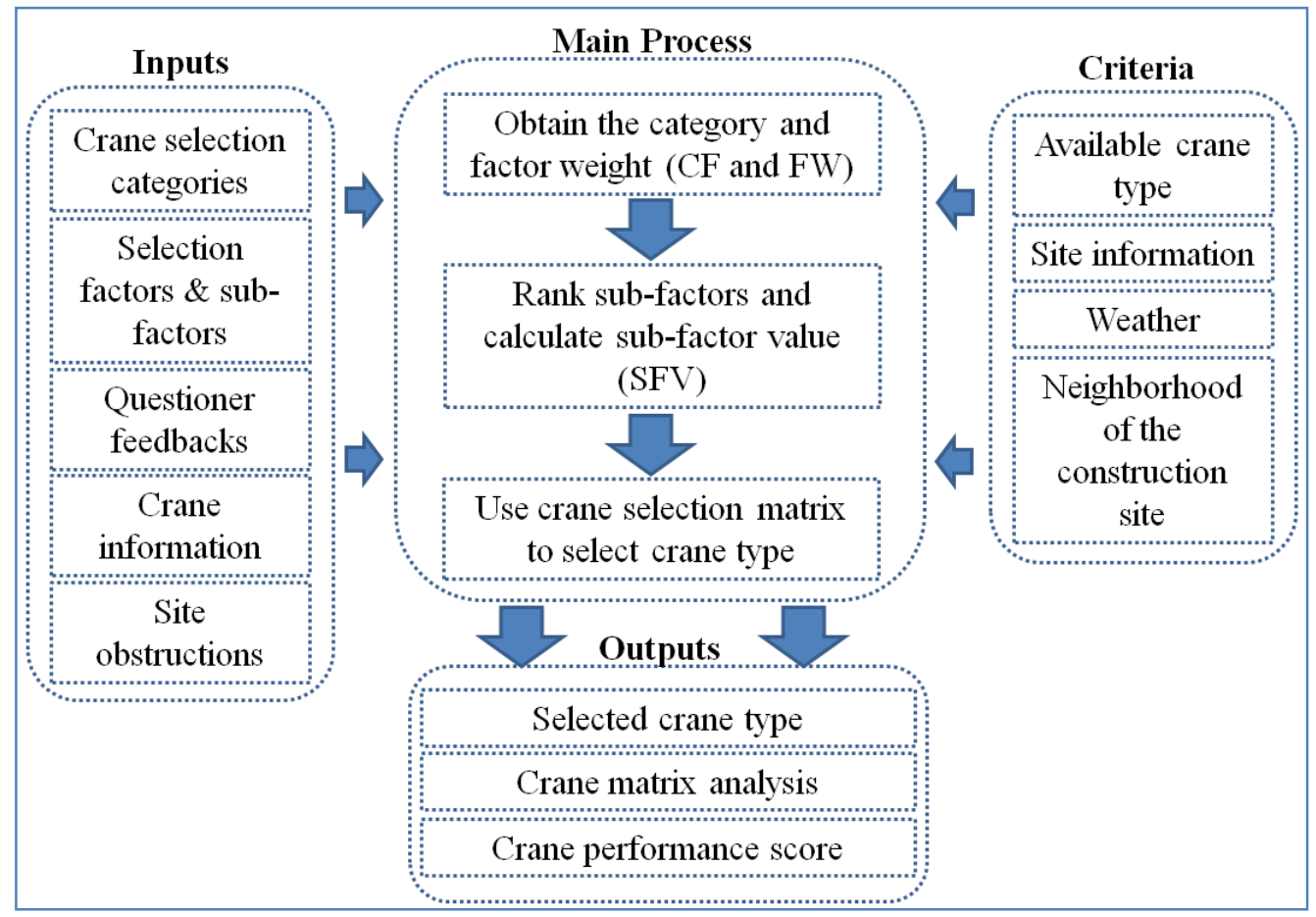

Figure 1 - Proposed methodology 


\section{FACTOR SELECTION AND RANKING}

In industrial projects, selecting a suitable crane is an important task in the initial stages of construction project planning since it has a major impact on project cost and scheduling related to project productivity. Previous research has been conducted regarding crane selection based on such critical factors as the crane capacity and project type. However, previous studies have not taken into account an exhaustive list of factors affecting crane selection but decide it based on the lifting engineer's experience. In this paper, a comprehensive list of factors is provided, based upon which a decision support matrix is used to select the optimal crane type which is a mobile crane versus tower crane. The matrix considers three main categories: (1) equipment and cost; (2) location and site; and (3) environmental impact. The "equipment and cost category" has to do primarily with the cost aspect of crane utilization, such as rental and installation expenses; the "location and site category" considers weather conditions, crane availability, spatial constraints, etc.; and the "environmental impact category" targets the energy consumption and pollution generated by the selected crane type. Various factors and sub-factors are considered for each category; (note that due to space limitations, not all sub-factors are listed in Table 1).

Table 1 - Categories and factors

\begin{tabular}{l|l}
\hline \multicolumn{1}{c|}{ Main Categories } & \multicolumn{1}{c}{ Factors } \\
\hline Equipment and cost & Cost (sub-factors: rental, transportation, installation expenses, etc.) \\
category & Installation \& Disassembly (sub-factors: time/difficulties in installation, etc.) \\
& Maintenance \& Depreciations (sub-factors: average breakdown cycle, etc.) \\
& Additional Safety Features/Technology (sub-factors: operator's skill, etc.) \\
\hline Location and site category & Weather (sub-factors: sub-factors: daily wind conditions, etc.) \\
& Availability (sub-factors: crane availability, etc.) \\
& Space (space requirement for installation, etc.) \\
& Support System (sub-factors: depreciation of support system, etc.) \\
& Transportation (sub-factors: transportation of the crane, etc.) \\
\hline Environmental impact & Energy (sub-factors: type of crane power, etc.) \\
category & Health (sub-factors: Noise \& dust) \\
& $\mathrm{CO}_{2}$ emission (sub-factors: $\mathrm{CO}_{2}$ emission at operation, etc.) \\
& Neighbor impact (sub-factor: privacy) \\
\hline
\end{tabular}

Both the categories and the factors are ranked based on questionnaire feedback. Figure 2 gives an example of category and factor ranking, while the percentages in Figure 2 indicate the importance of each category or factor for the given project. Each sub-factor is ranked by the project managers or engineers for each crane type being analyzed, according to four levels: (1) best option (weight=5); (2) good option (weight=4); (3) acceptable (weight=2.5); (4) somehow satisfy (weight=1); and (5) not satisfy (weight =0). Each level describes how suitable the analyzing crane type is for the project for that particular sub-factor. An example of sub-factor ranking is provided in Figure 3 for one specific crane. Based on the weights and ranking, the crane types are entered into the decision support matrix for selection analysis, which will be introduced in the following section.

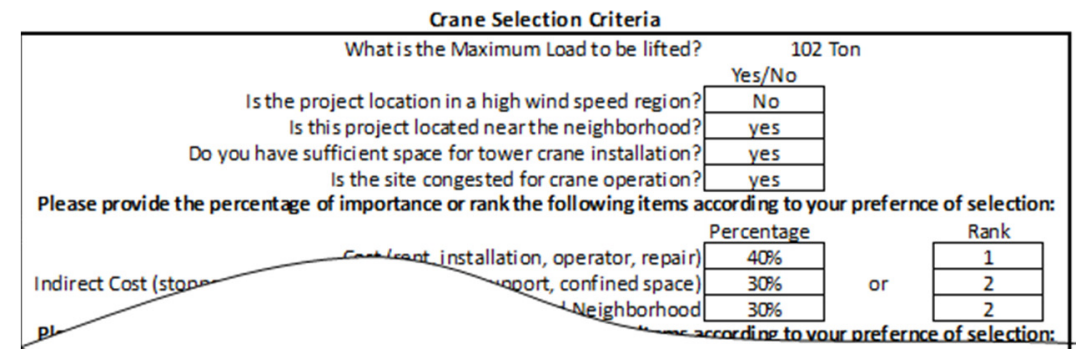

Figure 2 - Questionnaires for category and factor ranking 


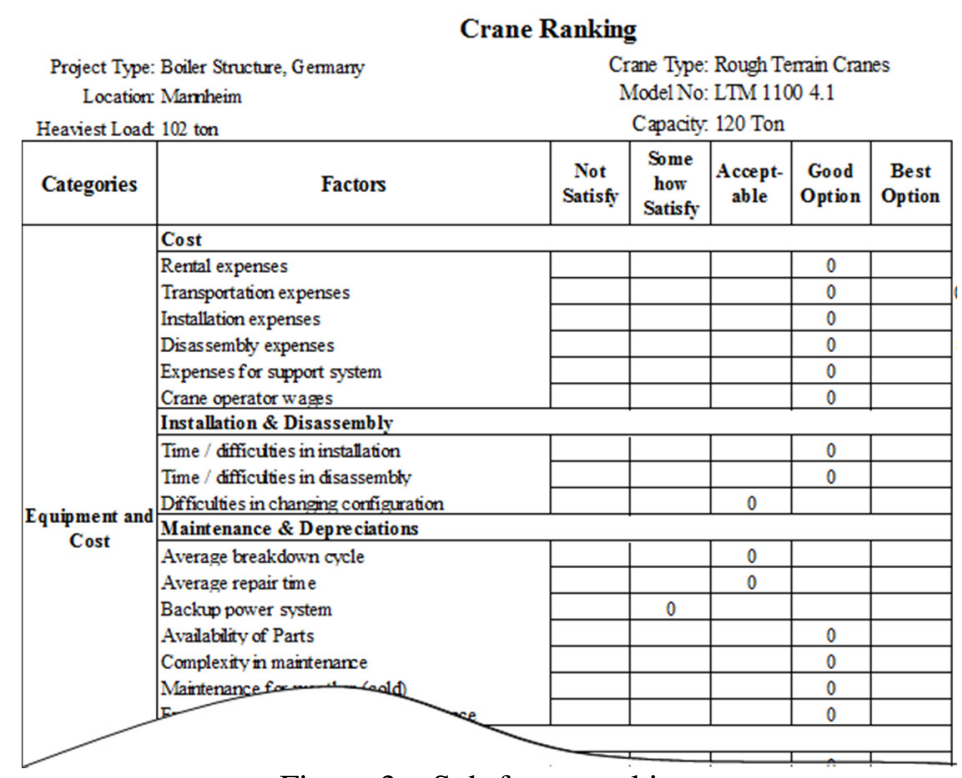

Figure 3 - Sub-factor ranking

CRANE SELECTION MATRIX MECHANISM

The crane selection matrix mechanisms calculate the sub-factor values for each type of crane type, and then calculate total scores for each crane type which are used to select the best crane. The relationship between sub-factors and crane type, and the count numbers for each sub-factor, are given in Equations (1) and (2), respectively. The Sub-Factor Value (SFV) is calculated satisfying Equation (3). After all the SFVs are calculated, the Crane Evaluation Score (CES) is calculated for each crane based on all the sub-factors, the Category Weight (CW), and the Factor Weight (FW), satisfying Equation (4). A screenshot from MS Excel is provided to illustrate CES calculation (Figure 4).

$$
\begin{gathered}
M_{S F V}=\left[\begin{array}{ccc}
S F V_{1}^{1} & \cdots & S F V_{1}^{j} \\
\vdots & \ddots & \vdots \\
S F V_{i}^{1} & \cdots & S F V_{i}^{j}
\end{array}\right] \\
M_{C N V}=\left[\begin{array}{ccc}
C N_{1}^{1} & \cdots & C N_{1}^{4} \\
\vdots & \ddots & \vdots \\
C N_{i}^{1} & \cdots & C N_{i}^{4}
\end{array}\right] \\
S F V_{i}^{j}=\frac{\sum\left(C N_{i}^{z} \times C N W_{i}^{z}\right)}{5 \times \Sigma C N_{i}^{z}(i=1 \text { to number of sub-factor under the same factor })} \\
C E S_{j}=\sum\left(C W_{x} \times \sum\left(\frac{\sum_{i=1}^{l} S F V_{i}^{j}}{l} \times F W_{y}\right)\right.
\end{gathered}
$$

Where: $M_{S F V}=$ sub-factor value matrix; $S F V_{i}^{j}$ is the sub-factor value for sub-factor $i$ and crane type $j$; $M_{C N V}$ is the count number value matrix; $C N_{i}^{Z}$ is the count number for sub-factor $i$ and level $z$ (four level: (1) best option; (2) good option; (3) acceptable; (4) somehow satisfy; and (5) not satisfy); $C N W_{i}^{Z}$ is the count number weight for sub-factor $i$ and level $z$ (weight for each level: (1) best option (weight=5); (2) good option (weight=4); (3) acceptable (weight=2.5); (4) somehow satisfy (weight=1); and (5) not satisfy (weight $=0)$ ); $C E S_{j}$ is the crane evaluation score for crane $j ; C W_{x}$ is the category weight for category $x$; $F W_{y}$ is the factor weight for factor $y$ and factor $y$ has a total of $l$ sub-factors. 


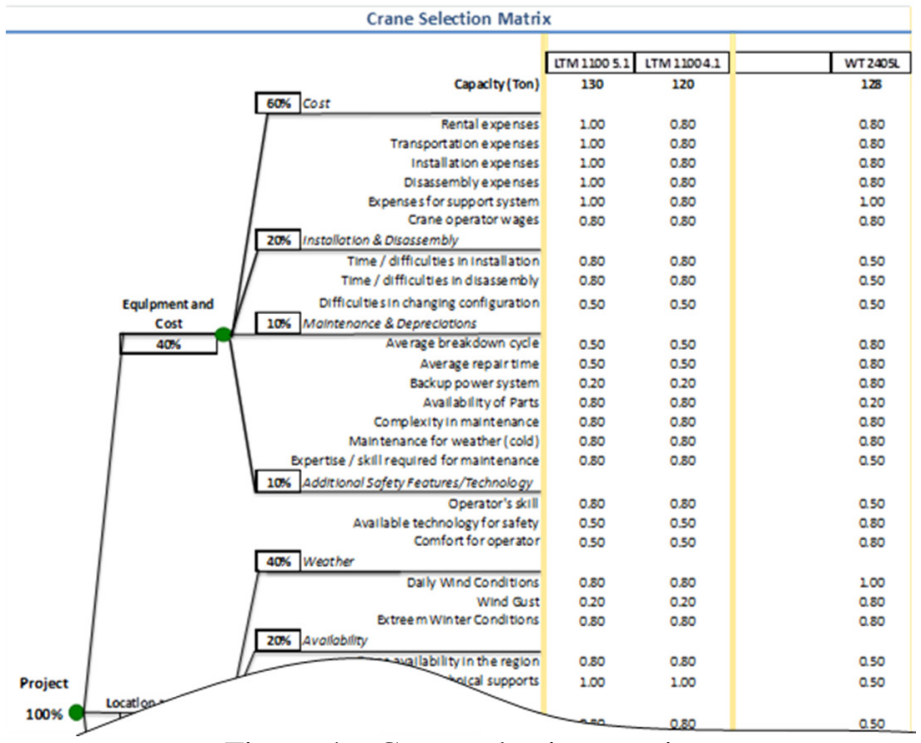

Figure 4 - Crane selection matrix

\section{CASE STUDY}

A case study-based approach has been utilized to demonstrate the proposed methodology. The methodology was tested in the planning and construction process for boiler house structures in Mannheim, Germany. The structures each consisted of five storeys ( $235 \mathrm{~m}$ x $290 \mathrm{~m}$ x $115 \mathrm{~m}$ ) which each storey had a different structure and height. There were some constraints involved in crane selection: (1) the greatest weight to be installed on top of the boiler structure in a single load was 102 tons (front and back bridge structures); (2) there were some site space limitations for crane location since the structures were to be assembled on-site; (3) the selected crane needed a sufficient radius to load and install structures at their final positions on the boiler structures. The assembly and storage areas were located in front of the structures, as shown in Figure 5a.

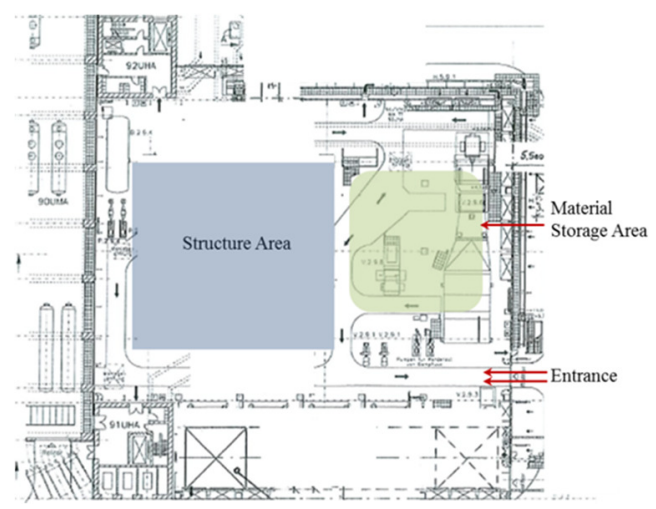

a. Original site layout

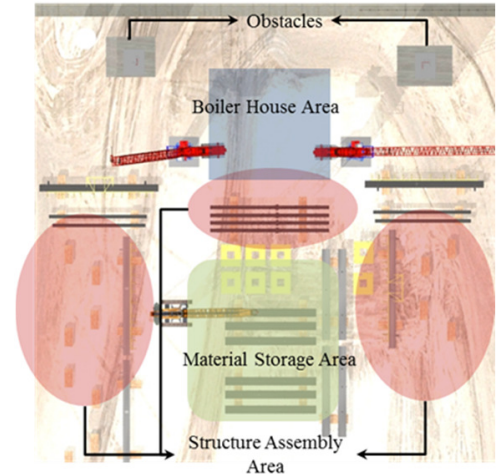

b. Proposed site layout with tower cranes

Figure 5 - Site layout of boiler structures in Mannheim

According to the procedures outlined in the methodology and given the project information, the crane selection criteria were designed based on the nature of the case study. The most important factors in this case were: (1) installation and disassembly in the equipment section and (2) space requirements for installation and movement in the site section, since the construction site offered limited space for crane location and operation. Therefore, the limitations in terms of on-site utilization and the availability of crane and technical support were highly ranked factors. After evaluating the crane selection criteria, the crane 
score was calculated to determine feasible cranes, which were a WT 2405L (128-ton) tower crane and an LTM 1100 (120-ton) mobile crane. The respective crane scores (Table 2) were $72 \%$ for the WT 2405L and $67 \%$ for the LTM 1100. The WT2405L was thus determined to be the best type for this certain project since it required less site space for crane location, installation, and disassembly than the mobile crane.

Table 2 - Feasible crane score

\begin{tabular}{|c|c|c|}
\hline \multicolumn{3}{|l|}{ Crane Score } \\
\hline Cost & 0.867 & \\
\hline Installation \& Disassembly & 0.500 & \\
\hline Maintenance \& Depreciations & 0.800 & \\
\hline Safety & 0.700 & \\
\hline Weather & 0.867 & \\
\hline Availability & 0.800 & \\
\hline Space & 0.933 & $72 \%$ \\
\hline Support System & 0.650 & \\
\hline Transportation & 0.800 & \\
\hline Energy & 0.700 & \\
\hline Health & 1.000 & \\
\hline $\mathrm{CO} 2$ & 0.600 & \\
\hline Neighboor & 0.200 & \\
\hline
\end{tabular}

A. WT $2405 \mathrm{~L}$

\begin{tabular}{c|r|c}
\hline \multicolumn{2}{c}{ Crane Score } & \\
\hline Cost & 0.800 & \\
Installation \& Disassembly & 0.700 & \\
Maintenance \& Depreciations & 0.629 & \\
Safety & 0.600 & \\
Weather & 0.800 & \\
Availability & 0.900 & \\
Space & 0.600 & $67 \%$ \\
Support System & 0.800 & \\
Transportation & 0.800 & \\
Energy & 0.425 & \\
Health & 0.500 & \\
CO2 & 0.400 & \\
Neighboor & 0.800 & \\
\hline
\end{tabular}

\section{B. LTM 1100}

The selected tower crane in this paper, WT 2405L, has the following specifications: (1) the capacity is 128 tons; (2) the maximum radius is $42 \mathrm{~m}$ and the minimum radius is $20 \mathrm{~m}$; (3) the selected crane features a $42-\mathrm{m}$ jib, which can move up and down to lift and/or load lifted objects, providing similar functionality to a mobile crane; (4) the counterweight moves up and down according to the jib movements; and (5) the maximum free-standing height is $75 \mathrm{~m}$, with the standard tower elements on the foundation. Therefore, the tower crane requires two bracing structures for stable lifting operations, but at different respective heights. In this case, the left tower crane required the bracing structures to be at $45.125 \mathrm{~m}$ and $87.125 \mathrm{~m}$, and the right tower crane required them to be at $48.325 \mathrm{~m}$ and $90.325 \mathrm{~m}$.

Based on the selected tower crane and project information, the visualization was implemented to design the proposed site layout (Figure 5b) and crane operations in order to identify constraints and eliminate feasible errors to ensure high productivity. The middle, right, and left sides of the front site area served as the structure assembly area where the leg and bridge structures were assembled by two tower cranes; one mobile crane assisted in delivering components of structures into the maximum radius area of tower cranes. The material storage area was located in the middle between the left and right assembly areas in order to supply material easily. Two obstacles were also discovered when tower cranes were rotated to load and place structures in position, which particularly affected the back side of the structures. The towers were located $7.9 \mathrm{~m}$ from front-center of the structure and $7 \mathrm{~m}$ from the side-centers. The sequences of tower crane operations illustrated in Figure 6a can be outlined as follows: (1) tower cranes on the two sides assemble the respective bridge structures; (2) a mobile crane assembles the leg structures and delivers them to within the maximum radius of the tower cranes; (3) the tower cranes lift the leg structures and place them in their respective positions if they are ready to be placed, even though the bridge structure is not assembled yet; and (4) the bridge structures are installed if they are ready.
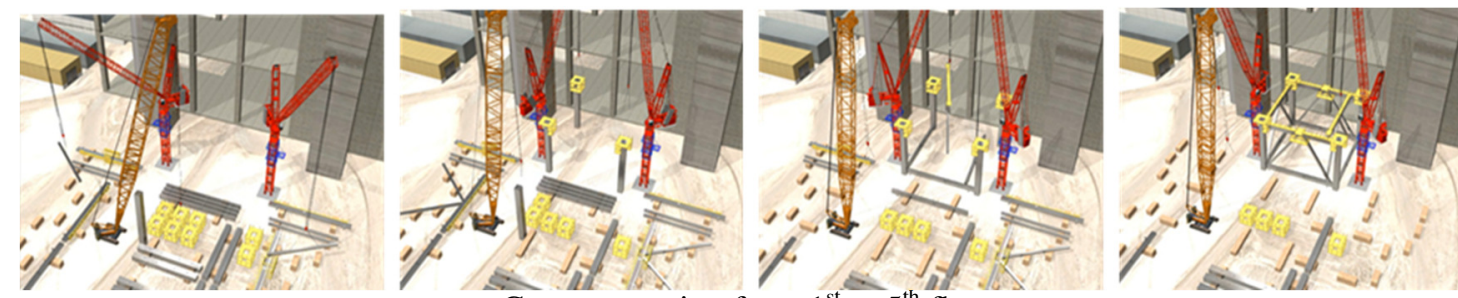

a. Crane operation from $1^{\text {st }}$ to $5^{\text {th }}$ floors 

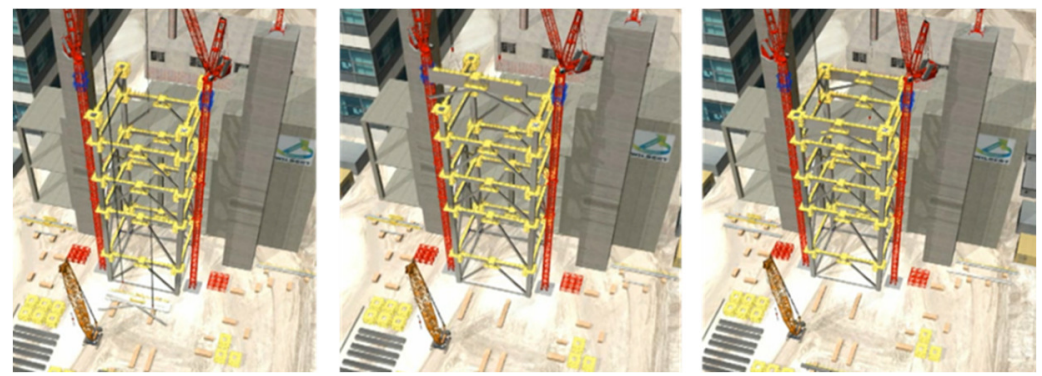

b. Crane collaboration

Figure 6 - The sequences of crane operations

Based on these sequences, the boiler structures were built from the 1st to the 5th floor. However, there were two challenges identified during the visualization. It was determined that a feasible collision between the crane and obstacles may occur when the cranes were carrying the bridge structures for the back, left, and right sides into position. To prevent these errors, either the crane should be rotated to the front side (where there is no obstacle) or the jib should be raised to provide sufficient clearance. As shown in Figure 6b, the other challenge was that two tower cranes were required to collaborate in order to lift and install front and back bridge structures, which were 102 tons, on to the top floor. In practice a major collision could have occurred at this stage in the assembly process, and this underscores the value of visualization as a proactive tool to assist crane operators in reducing operational errors. Based on these outputs from the proposed methodology, the use of two tower cranes was selected for a quick and safe assembly process, and was successfully implemented in practice as illustrated in Figure 7.
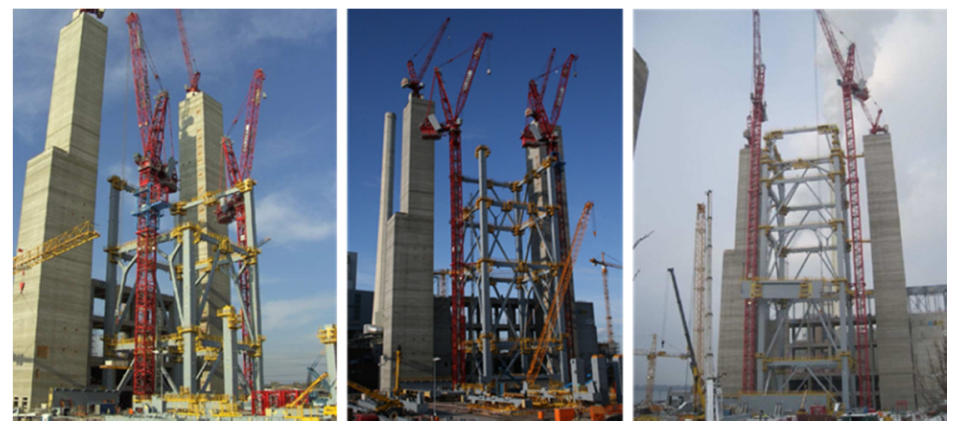

Figure 7- Crane operation in practice

\section{CONCLUSIONS}

In current practice, crane selection is carried out by lift engineers who draw on their experience to determine the heaviest lift and/or the largest lifting radius for identified cranes. This practice is relatively time-consuming, and optimization of the crane's use and location is also difficult. Therefore, a framework as a decision support system to select the best possible cranes and identify spatial conflict-free locations on site is necessary to facilitate productivity and safety improvements for large-scale industrial construction projects. There are many factors, such as environmental, site, and equipment factors, which need to be considered during the crane selection process, a reality which further complicates the process. This paper utilizes an innovative crane selection matrix with more than 40 factors in order to establish a process for optimized crane selection in large-scale industrial construction projects. A visualization model to simulate crane operations and identify collision-free crane operation paths is proposed to validate the crane selection. In the case study, the selected crane, WT2405L, was identified and the visualization was built to plan the lifting process effectively and efficiently by identifying and removing potential errors. The visualization entailed (1) lifting a 102-ton load onto the top of the boiler structure using two cranes in collaboration and (2) presenting on-site space limitations related to crane selection, location, and operation. Based on the 
project constraints, the proposed crane selection framework, and the visualization models, two tower cranes were selected and successfully implemented in the case study.

\section{ACKNOWLEDGEMENTS}

The financial support of NSERC is gratefully acknowledged. The authors appreciated the assistance from Northern Crane Services, Edmonton, Canada and Wilbert Cranes, Germany.

\section{REFERENCES}

Al-Hussein, M., Alkass, S., \& Moselhi, O. (2001). An algorithm for mobile crane selection and location on construction sites. Construction Innovation: Information, Process, Management, 1(2), 91-105.

Chang, Y., Hung, W., \& Kang, S. (2012). A fast path planning method for single and dual crane erections. Automation in Construction, 22, 468-480.

Hanna, A., \& Lotfallah, W. B. (1999). A fuzzy logic approach to the selection of cranes. Automation in Construction, 8, 597-608.

Hasan, S., Bouferguène, A., Al-Hussein, M., Gillis, P., \& Telyas, A. (2013). Productivity and $\mathrm{CO}_{2}$ emission analysis for tower crane utilization on high-rise building projects. Automation in Construction, 31, 255-264.

Hermann, U., Hendi, A., Olearczyk, J., \& Al-Hussein, M. (2010). An integrated system to select, position, and simulate mobile cranes for complex industrial projects. Construction Research Congress 2010 (pp. 267- 276), ASCE, Banff, Alberta, Canada.

Huang, C., Wong, C. K., \& Tam, C. M. (2011). Optimization of tower crane and material supply locations in a high-rise building site by mixed-integer linear programming. Automation in Construction, 20, 571-580.

Kang, S., \& Miranda, E. (2006). Planning and visualization for automated robotic crane erection processes in construction. Automation in Construction, 15, 398-414.

Lei, Z., Taghaddos, H., Hermann, U., \& Al-Hussein, M. (2013). A methodology for mobile crane lift path checking in heavy industrial projects. Automation in Construction, 31, 41-53.

Olearczyk, J., Al-Hussein, M., Bouferguène, A., \& Telyas, A. (2012). 3D-modeling for crane selection and logistic for modular construction on-site assembly. International Conference on Computing in Civil Engineering, Clearwater Beach, FL, 445-452.

Safouhi, H., Mouattamid, M., Hermann, U., \& Hendi, A. (2011). An algorithm for the calculation of feasible mobile crane position areas. Automation in Construction, 20, 360-367.

Sawhney, A., \& Mund, A. (2002). Adaptive probabilistic neural network-based crane type selection system. Journal of Construction Engineering and Management, 128 (3), 265-273.

Sivakumar, P. L., Varghese, K., \& Babu, N. R. (2003). Automated path planning of cooperative crane lifts using heuristic search. Journal of Computing in Civil Engineering, 17(3), 197-207.

Taghaddos, H., AbouRizk, S., Mohamed, Y., \& Hermann, U. (2012). Simulation-based auction protocol for resource scheduling problems. Journal of Construction Engineering and Management, 138(1), 31-42.

Wu, D., Lin, Y., Wang, X., Wang, X., \& Gao, S. (2011). Algorithm of crane selection for heavy lifts. Journal of Computing in Civil Engineering, 25(1), 57-65. 